\title{
Francisco Pompêo do Amaral: médico, jornalista, professor e escritor científico no campo da alimentação e da nutrição no Brasil
}

\author{
Francisco Pompêo do Amaral: doctor, journalist, teacher and science writer in the field \\ of food and nutrition in Brazil
}

Maria Lucia Mendes de Carvalho

Coordenadora do Projeto Memórias e História da Educação Profissional do Centro Paula Souza. Atualmente faz pósdoutorado no Museu de Astronomia e Ciências Afins maria.mendes@cps.sp.gov.br

Resumo: O presente trabalho aborda a importância de Francisco Pompêo do Amaral (1907-1990), enquanto jornalista, escritor, nutrólogo e sociólogo no campo da alimentação e nutrição no Brasil. Em 1939, Pompêo do Amaral foi contratado como médico chefe da Superintendência do Ensino Profissional do Estado de São Paulo, criando o primeiro curso de formação de técnicos em alimentação no país. Este trabalho objetiva divulgar, por meio de suas obras publicadas em livros e artigos em revistas científicas, essa primazia, pois quase não existem registros sobre a origem desse curso, cuja aula inaugural foi em 17 de maio de 1939. Como intelectual, esse médico e professor foi um dos fundadores e colaborador da Revista Brasiliense, entre 1955 e 1965. Nesse período, a Livraria José Olympio Editora, conhecida por publicar grandes escritores e intelectuais brasileiros, publicou três obras premiadas em nível nacional de Pompêo do Amaral, relacionadas com a qualidade da alimentação da população brasileira.

Palavras Chaves: Alimentação, Nutrição, Historiografia, Intelectuais.

\begin{abstract}
This paper discusses the importance of Francisco Pompêo do Amaral (1907-1990), as a journalist, writer, sociologist and nutrition specialist in the field of food and nutrition in Brazil. In 1939 he was hired as chief medical officer of the Superintendência do Ensino Profissional do Estado de São Paulo, creating the first training course for food technicians in the country. We aim to analyze his pioneering role, through his works published in books and articles in scientific journals, since there are few records of the origin of that course, whose inaugural lecture was held on May 17, 1939. As an intellectual, this doctor and professor founded and was one of the contributors of the Revista Brasiliense, between 1955 and 1965. During this period, Livraria José Olympio Editora, known for publishing major Brazilian writers and intellectuals, has published three books nationally award-winning by Pompêo do Amaral, related to the quality of food of Brazilian population.
\end{abstract}

Keywords: Food, Nutrition, Historiography, Intellectuals. 
Francisco Pompêo do Amaral nasceu em novembro de 1907, em Piracicaba, e formou-se na turma de 1932, pela Faculdade de Medicina de São Paulo, hoje da Universidade de São Paulo. Ainda estudante, trabalhou na campanha de profilaxia da febre amarela, levada a efeito pelo Serviço Sanitário do Estado de São Paulo em 1929. Durante a Revolução Constitucionalista, serviu como médico no Regimento Esportivo, por designação das autoridades competentes. Em 1933, apresentou, perante banca nomeada pela faculdade, a "tese inaugural”, orientada pelo professor Almeida Prado, para a Cadeira de Clínica Médica e Propedêutica da Faculdade de Medicina de São Paulo, sendo aprovado com distinção (POMPÊO DO AMARAL, 1957).

Entre 1933 e 1934, Francisco Pompêo do Amaral atuou como médico, orientando, no Parque Pedro II, as crianças que praticavam exercícios físicos. Nesse período, organizou um fichário institucional, incluindo as condições de vida dessas crianças, que foi apresentado como tese, intitulada “Considerações em torno do problema da educação física da infância em idade escolar no Estado de São Paulo", na Conferência Nacional de Proteção à Infância, realizada no Rio de Janeiro, em 1933, posteriormente publicada no Anuário de Higiene (POMPÊO DO AMARAL, 1963b). Em 1934, ingressou na Cruzada Pró-Infância, iniciativa que surgiu quando a educadora sanitária Maria Antonieta de Castro entrou em contato com Pérola Byington, senhora da "alta sociedade" em São Paulo, e, juntas, decidiram se associar para combater as altas taxas de mortalidade, principalmente infantil, devido a doenças infectocontagiosas, como tifo, diarreia, pneumonia e tuberculose. O grupo inicial reuniu cem senhoras que fundaram a Cruzada Pró-Infância, em 12 de agosto de 1930 (MOTT, 2003).

Assim que ingressou na Faculdade de Medicina de São Paulo, Francisco Pompêo do Amaral começou a atuar profissionalmente como jornalista. Em janeiro de 1934, prestava serviços aos jornais Folha da Manhã, Folha da Tarde, Folha da Noite e Folha de São Paulo, com a finalidade de vulgarizar os conhecimentos de higiene para a população e promover intensa campanha em prol da racionalização da alimentação popular, o que possibilitou divulgar em outros jornais nacionais suas matérias. Um ano depois, foi contratado como professor no curso para "Instrutores de Ginástica", em São Paulo, o qual deu origem ao primeiro curso de Educação Física na Universidade de São Paulo (MASSUCATO e BARBANTI, 1999).

Como médico, jornalista, professor, escritor e sociólogo construiu com relevância as suas obras (CARVALHO, 2013). Durante o período em que atuou como professor na 
Escola Superior de Educação Física, entre 1934 e 1938, escreveu artigos que foram publicados pela Folha da Manhã, em São Paulo, abordando o aspecto médico-higiênico da educação física. Para Edward Said “[...] os intelectuais necessitam de uma vocação, seja para arte de representar, seja para escrever, falar, ensinar [...] passa a ser reconhecível publicamente e se envolve ao mesmo tempo com compromisso e risco de representar certa opinião" (apud BARONI, 2014: 25-26).

Em janeiro de 1939, foi contratado como médico chefe da Superintendência do Ensino Profissional do Estado de São Paulo, criando o primeiro curso de formação de técnicos em alimentação no país (CARVALHO \& FAGNANI, 2014). Este curso foi formalizado pelo Decreto Estadual $\mathrm{n}^{\circ} 10.033$, de 3 de março do corrente ano, com a aprovação dos programas dos cursos de "Educação Doméstica e Dietética para Donas de Casa" e de "Formação de Mestras de Educação Doméstica e Auxiliares em Alimentação" (POMPÊO DO AMARAL, 1939). Na aula inaugural dos cursos de Dietética, em 17 de maio de 1939, Pompêo do Amaral declarou no seu discurso:

[...] para enfrentarmos o complexo problema da racionalização da alimentação popular, precisamos formar pessoal capaz para dirigir a ação. Foi o que reconheceu a Superintendência do Ensino Profissional, que tratou de, quanto antes, agir junto ao atual governo, no sentido de obter o preenchimento da lacuna que lamentavelmente existia. E foi assim que se organizou o "Curso de Auxiliares em Alimentação", que ora se inaugura. Ele não formará cientistas naturalmente, porém, habilitará, cada ano, uma plêiade de bons técnicos perfeitamente em condições de desenvolver, com entusiasmo - um trabalho utilíssimo junto à nossa população. Colocado entre as atividades do Curso de Aperfeiçoamento das Escolas Profissionais - destinados ao preparo de professoras especializadas, para o ensino e direção de estabelecimentos congêneres, em nosso Estado - esse curso será ministrado exclusivamente às alunas que pretenderem dedicar-se à nova profissão (1939a: 7).

Naquele mesmo ano, Pompêo do Amaral publicou o livro Comer para viver (Imagem 1) com a finalidade de divulgar conhecimentos à população de modo a permitir alimentarem-se racionalmente, como indicado no prefácio do jornalista Rubens do Amaral: 
O problema brasileiro é tríplice, mas indivisível: educação, saúde e riqueza. Analfabeto, enfermo e pobre, um povo não progredirá. Nem estacionará, sequer. Como, porém, se montará o aparelhamento da educação, que exige muito dinheiro, se a pobreza predomina? E como se enriquecerá um país, se os seus filhos, além de achacados de nem sabemos quantas endemias, nem ao menos se alimentam suficientemente [...] O dr. Francisco Pompêo do Amaral, escrevendo para o povo um livro que pode ser lido pelos cientistas, expôs os princípios gerais da alimentação racional, examinou as falhas atualmente existentes nos nossos costumes e terminou propondo, para uso das classes populares, a polenta de milho com leite, que dá um alimento mais completo do que outros pratos exóticos que, no entanto, gozam de grande favor entre nós porque ainda temos alma colonial e cultuamos o que nos vem das antigas metrópoles europeias, por moda, por hábito, por preguiça. (AMARAL, 1939: $13)$.

\section{Imagem 1}

Capa do livro Comer para viver, de 1939.

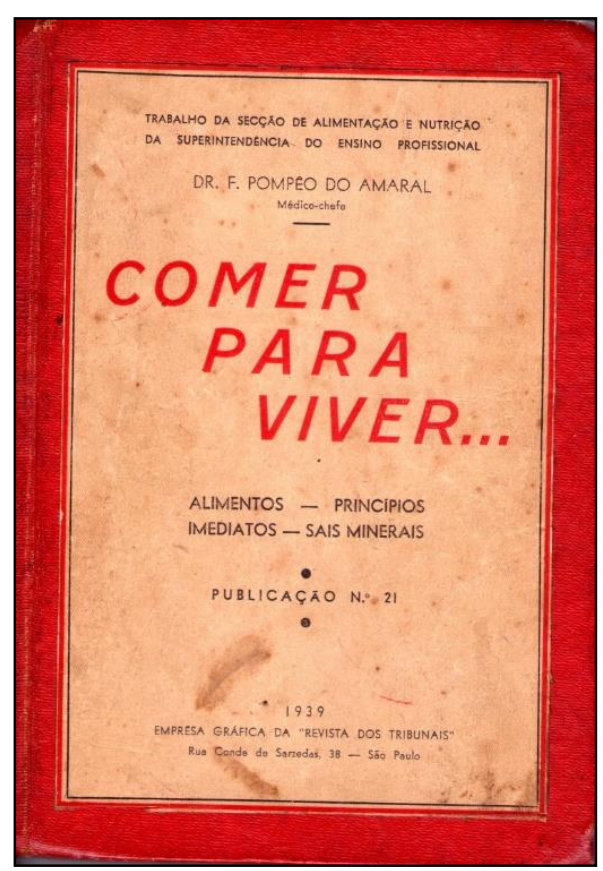

Fonte: POMPÊO DO AMARAL, 1939b: capa [reprodução].

Como médico, Pompêo do Amaral esteve engajado nas atividades da Academia de Medicina de São Paulo, sucessora da Sociedade de Medicina e Cirurgia de São Paulo, fundada em março de 1895, cuja finalidade era preservar a tradição, a história e o progresso da medicina e das ciências afins. Na Seção de Higiene e Medicina Tropical da 
Associação Paulista de Medicina, em 4 de julho de 1939, apresentou a comunicação "Os cursos de dietética da Superintendência do Ensino Profissional de São Paulo”. Em 1939, candidatou-se a uma vaga na Seção de Medicina Geral da Sociedade de Medicina e Cirurgia de São Paulo, conseguindo tornar-se um dos trinta acadêmicos. O discurso do médico João Alves de Meira, empossando o novo titular, desvelava o perfil de Pompêo do Amaral: “[...] Deste convívio em que você soube se impor pelo seu valor e pelos seus dotes Morais e intelectuais pude aquilatar da sua firmeza de caráter, da retidão de suas atitudes, dá inteireza de seu proceder, da robustez de suas convicções e de tantas outras qualidades que formam o seu espírito e a sua personalidade" (MEIRA, 1939: 218).

No início da década de 1940, Pompêo do Amaral realizou estudos e pesquisas sobre a alimentação do povo brasileiro, enfatizando a importância do milho na produção de pães, em substituição à importação de trigo, publicados na Revista Brasileira Agrícola. Também discutiu nesses artigos as fraudes na produção industrial de alimentos e as melhorias para produção e comercialização do leite e seus derivados (POMPÊO DO AMARAL, 1941, 1942, 1942a, 1942b e 1942c).

As matérias jornalísticas, bem como os artigos científicos publicados na Folha da Manhã e na Revista Agrícola Brasileira, permitem identificar que a problematização sobre a alimentação do povo brasileiro fez parte da trajetória social e profissional desse intelectual.

Francisco Pompêo do Amaral era um profissional engajado politicamente com as associações de classe, enquanto médico, e com a população, enquanto jornalista na Folha da Manhã. Isto pode ser percebido pelos seus trabalhos apresentados na Academia Paulista de Medicina ou pelas matérias jornalísticas no campo da alimentação e da nutrição, publicadas na impressa. Os artigos que Francisco Pompêo do Amaral publicou na Revista Agrícola Brasileira, na sua maioria, eram reproduções de matérias jornalísticas da Folha da Manhã e intitulavam-se, por exemplo, "O fubá integral e a alimentação do povo brasileiro" ou "Que pode ter a manteiga?" Eles demonstravam a intenção do médico em divulgar, para a população e a comunidade científica, os conhecimentos sobre as práticas de educação alimentar e nutricional para fins de uma alimentação saudável.

As obras de Francisco Pompêo do Amaral mostram como é possível, a partir das práticas pedagógicas e escolares e com apoio institucional, fornecer elementos para a pesquisa no campo da alimentação e nutrição. Como médico-chefe do setor de Serviços Médicos e responsável pela Seção de Alimentação e Higiene Escolar na Superintendência do Ensino Profissional do Estado de São Paulo, atuou com a sua equipe de dietistas, 
realizando atividades de pesquisa e de magistério no Instituto Profissional Feminino ${ }^{1}$, na capital (LAURINDO, 1962: 216). Entre os livros que publicou, está Alimentação conferências, que inclui diversas conferências proferidas em 1941, durante a "Jornada sobre Alimentação" promovida pelo Instituto de Organização Racional do Trabalho $(\text { IDORT })^{2}$ (POMPÊO DO AMARAL, 1941a). Como um exemplar desta obra existe no acervo do Centro de Memória da Escola Técnica Estadual Carlos de Campos, foi possível conhecer os títulos e os conteúdos das conferências: "Consequências da má alimentação do operário"; "A alimentação do intelectual"; "Os dentes e a alimentação"; "A ação da Superintendência do Ensino Profissional de S. Paulo, em favor da racionalização da alimentação"; e "A desnutrição entre os escolares" (Ibid.).

Em 1942, em matéria para o jornal Folha da Manhã, cuja manchete era "UMA AÇÃO TRIUNFANTE" "3, Francisco Pompêo do Amaral escreveu sobre a contratação de profissionais do curso de "Auxiliares em Alimentação" pelo mercado de trabalho, indicando a implementação do Decreto-Lei $\mathrm{n}^{\circ} 1.238$, de 2 de maio de 1939, pelas indústrias de alimentação:

A capacidade das referidas técnicas está perfeitamente comprovada pelo êxito com que veem atuando nos diversos encargos que lhes têm sido conferidos. Das 71 alunas diplomadas até esta data, pelo menos 24 já desempenham funções com inteiro agrado, por parte daqueles aos quais compete a direção das mesmas. Dezesseis se ocupam com os trabalhos do Curso de Dietética para Donas de Casa e outras prestam serviços remunerados a instituições beneficentes (creches, etc.) bem como a particulares. $\mathrm{O}$ adiantado industrial Brasílio Machado Neto acaba de entregar a direção do refeitório de uma de suas fábricas à d. Ione Cintra de Souza, uma das melhores técnicas preparadas pela Superintendência do Ensino Profissional e nos é particularmente grato assinalar as boas referências que nos foram transmitidas pela gerência da Casa de Saúde 'Pedro II', sobre a atuação de uma das jovens mais recentemente

\footnotetext{
${ }^{1}$ O Instituto Profissional Feminino é originário da primeira Escola Profissional Feminina, da cidade de São Paulo, criada em 1911, denominada Escola Técnica Estadual (Etec) Carlos de Campos, desde 1994.

${ }^{2}$ Segundo Tenca, o "discurso da Organização Científica do Trabalho, no Brasil, ganha força somente no fim da década de 1920, e passa a ser disseminado de maneira mais efetiva a partir de 1931, com a criação do Instituto de Organização Racional do Trabalho (IDORT), logo após a sua criação, em 1929, do Centro das Indústrias do Estado de São Paulo (Ciesp), polo aglutinador da grande indústria” (2006: 30-31).

${ }^{3}$ Destaque do original.
} 
habilitadas, d. Julieta Terlizzi, que ocupa o cargo de chefe de alimentação do estabelecimento (POMPÊO DO AMARAL, [1942]: s. p.).

Quando Francisco Pompêo do Amaral foi comissionado para a Secretaria da Agricultura, em 14 de junho de 1941, também foi indicado como membro da Comissão de Alimentação Pública, instituída pelo governo do estado de São Paulo. Nessa Secretaria, escreveu vários trabalhos institucionais que foram publicados, entre eles $A$ vitamina “A” (Imagem 2) (1942) e Para melhorar a alimentação da população paulista, este último lido na sessão da Comissão de Alimentação Pública em 19 de junho de 1941, um documento com 26 páginas (POMPÊO DO AMARAL, 1963b).

\section{Imagem 2}

Capa do livro A vitamina “ $A$ ”, de 1942.

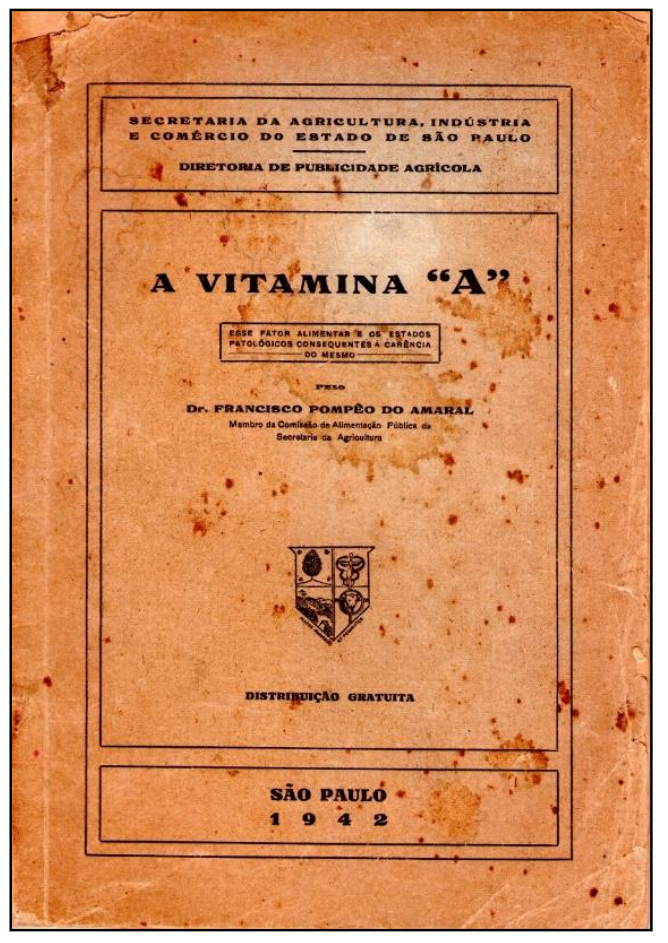

Fonte: POMPÊO DO AMARAL, 1942: capa [reprodução].

Francisco Pompêo do Amaral, na seção de Alimentação e Nutrição da Superintendência do Ensino Profissional, produziu as obras Alimentação - conferências, já referida, e O problema do leite em São Paulo, este apresentado e debatido na sessão da Comissão de Alimentação Pública, em 25 de setembro de 1941. O conteúdo apresentando na conferência "O problema do leite em São Paulo" gerou um trabalho de quarenta páginas, em 1942 (POMPÊO DO AMARAL, 1963b). 
Ainda em 1941, Francisco Pompêo do Amaral organizou e inaugurou, em 11 de novembro, a "Exposição de Alimentação"4, que, segundo esse médico, foi um certame de caráter educativo exclusivamente, sendo o primeiro no gênero no país. Depois do sucesso da exposição, foi designado pelo governo do estado de São Paulo para participar da comissão encarregada de estudar o comércio, a higiene e a fiscalização do leite e derivados. Mas, em 22 de abril de 1942, ao perceber que não pretendiam executar a praxe necessária para tais exigências, comunicou o seu desligamento da comissão, por carta, ao interventor federal do estado (POMPÊO DO AMARAL, 1963b).

Horácio Augusto da Silveira, superintendente do ensino profissional, e o médico Francisco Pompêo do Amaral foram comissionados junto à Secretaria de Agricultura, ainda em 1942, para prestar serviços na organização das escolas práticas de agricultura, planejadas pelo governo Fernando Costa, em função da experiência adquirida no funcionamento das escolas agrícolas pelo primeiro, criadas em Pinhal, Jacareí e em São Manuel, entre 1935 e 1939 (LAURINDO, 1962).

Francisco Pompêo do Amaral foi convocado pela Chefia do Estabelecimento de Subsistência da $2^{\mathrm{a}}$ Região Militar para estudar o problema da alimentação no Exército em geral e, em particular, o das rações de reserva. Em função dessa convocação, criou e ministrou o curso de "Alimentação de Guerra", promovido pela Superintendência do Ensino Profissional para as jovens da Legião Brasileira de Assistência, em 1943. Ainda neste ano, escreveu o livro $O$ problema da alimentação do soldado. Rações de reserva, publicado pelo Ministério da Guerra (POMPÊO DO AMARAL, 1963b).

Entre 1944 e 1945, o médico apresentou comunicações na Sociedade de Medicina e Cirurgia de São Paulo na área de sua especialização, sendo, posteriormente, publicadas na Revista de Medicina e Cirurgia de São Paulo. Em 1 de agosto de 1944, proferiu a palestra "A alimentação da população no momento que atravessamos", como membro desta Sociedade, e chamou a atenção para a questão de grande importância, sob o aspecto higiênico, social e econômico, dizendo: "Não somos dos que descreem sistematicamente na ação dos governos e podemos testemunhar até os bons propósitos revelados pelo Interventor Fernando Costa, ao encaminhar, ainda há poucos dias, com todo o acerto, a questão do pão de guerra" (POMPÊO DO AMARAL, 1944: 35).

Em "A Faculdade de tipo norte-americano que agora temos" (POMPÊO DO AMARAL, 1945) percebe-se a forma pernóstica que o médico Pompêo do Amaral

\footnotetext{
${ }^{4}$ A Exposição de Alimentação, em São Paulo, teve repercussão no exterior, sendo noticiada na Revista Viva Cien Ânos, de Buenos Aires, ano 8, vol. XIII, n 6, p.355-357, p.389 (POMPÊO DO AMARAL, 1963b).
} 
utilizou para se dirigir aos seus colegas de profissão e da academia, criticando estudos e pesquisas de determinados médicos, principalmente, sobre a substituição do leite de origem animal por alimentos à base de soja. O Dr. Carlos Foá, da Universidade de Milão, que esteve presente na aula inaugural do curso de "Auxiliares em Alimentação", em 17 de maio de 1939, realizado no Instituto Profissional Feminino, no Brás, em São Paulo, foi contestado no texto dessa comunicação, indicando os modos que o médico Pompêo do Amaral utilizava para dialogar com os seus pares.

É possível, no entanto, que não tenhamos razões para nos preocuparmos com a situação de carência de leite, bem como com a escassez de seu consumo, que chega a assustar a generalidade dos pediatras, dietólogos e higienistas. Em São Paulo, o consumo de leite, antes do início desta guerra e não no momento, era orçado em pouco mais de 100 cc., por dia e por pessoa. Nos países escandinavos e no Canadá, ascende a 600-800 cc. Consumo equivalente se encontra nos Estados Unidos, onde MC COLLUM e SIMMONDS preconizam um litro de leite, por dia e por pessoa. Na Finlândia, uma das nações mais bem alimentadas do mundo, ele atinge $1.430 \mathrm{cc}$., o que significa que, num só dia, o finlandês médio ingere o leite que um brasileiro médio demora dois meses e meio para beber. O dr. CARLOS PRADO, com efeito, acusa ser de $20 \mathrm{cc}$, por dia e por pessoa, a média do consumo do leite no Brasil! É possível que não tenhamos razões para nos preocuparmos com a situação de carência de leite - íamos dizendo - porque o dr. CARLOS ALBERTO DO ESPÍRITO SANTO anda atormentado justamente com o contrário e, ainda há pouco tempo, foi à Sociedade Rural discorrer sobre "o máximo de leite tolerável na ração". ${ }^{5}$ E o Prof. CARLOS FOÁ, em experiências que: merecem ficar consignadas nos anais desta sociedade, alimentou doze crianças, com idades de 25 a 40 meses, com dieta a base de soja. Essa prova parece-nos de valor limitado, uma vez que, através dela, não se fica sabendo, por exemplo, como se comportariam as mesmas crianças ou outras semelhantes, com dieta à base de bom leite de vaca, alimento unanimemente aceito como insubstituível pelas autoridades na matéria. Por isso mesmo, não se pode deixar de reconhecer excessivamente precipitada a conclusão de um autor

\footnotetext{
${ }^{5}$ Pompêo do Amaral informa em nota que o Dr. Carlos Alberto do Espírito Santo abordou esse tema em reunião da Sociedade Rural, conforme noticiou a Folha da Manhã, em 1 de dezembro de 1943, em São Paulo (1944).
} 
mencionado, de que "as proteínas da soja são capazes de substituir o leite..." (POMPÊO DO AMARAL, 1944: 32). ${ }^{6}$

Ainda em "A alimentação da população no momento que atravessamos", Francisco Pompêo do Amaral criticou a atuação do médico Josué de Castro que, em 1944, era o diretor do Instituto de Tecnologia Alimentar, criado no Rio de Janeiro, por iniciativa do Serviço Técnico em Alimentação (MELO e NEVES, 2007: 280):

O dr. JOSUÉ DE CASTRO, do Serviço Técnico em Alimentação Nacional, esteve, há dias, nesta casa. Considerou, a julgar-se pelas notícias da imprensa, que "enquanto o trabalhador brasileiro não tiver capacidade aquisitiva que o permita comer carne, ovos e leite que o supram de proteínas e frutas e verduras que o forneçam de vitaminas", o problema de sua alimentação será gravíssimo. Não obstante, prepara o seu serviço "medidas" adicionais, que implicam na fabricação e distribuição de milhões de comprimidos, contendo vitaminas e proteínas altamente concentradas por processos de "desidrolização", etc. Sem dúvida alguma, estamos borboleteando em torno de situação, o dramática. - Porque - perguntamos - o nosso trabalhador não poderá comer carne, leite e ovos e precisará ser mantido com pílulas e concentrados capazes de melhorar, sem dúvida, a alimentação de seus fabricantes, bem como a dos seus aliados? Estamos nós, aqui, para assistir, pusilânimes à transformação deste povo, com uma tradição de bravura, que é a nossa gente, que será o Brasil do futuro, numa coletividade de hindus?! Já GEOFFROY SAIINT-HILAIRE mostrava que, quando uma dieta é excessivamente vegetal -é, em uma palavra, uma dieta pobre de leite, de carne e de ovos - enfraquece a inteligência e deprime a energia moral. "Vede a Irlanda e vede a Índia! - convidava ele. A Inglaterra não poderia reinar pacificamente sobre um povo devastado, se a batata, quase não ajudasse esse povo a prolongar a sua lamentosa agonia. Cento e quarenta milhões de indus (sic) não obedeceriam a alguns milhões de ingleses, se se alimentassem como eles". À Sociedade de Medicina de S. Paulo, meus senhores, não lavará as mãos em face de uma situação desta natureza. Saberá honrar sua tradição. Não consentirá que se continue a privar-nos do que nos é essencial - carne, ovos,

${ }^{6}$ Pompêo do Amaral (1944) informa em nota que o Dr. Carlos Foá publicou esse estudo como artigo "O feijão soja na alimentação do homem e do gado" na Resenha Clínico-Científica de 1 de janeiro de 1943. 
leite - e a experimentar substituí-los por soja, castanha do Pará, alfafa ou faveiro (POMPÊO DO AMARAL, 1944: 34-35) ${ }^{7}$.

Em 1944, Francisco Pompêo do Amaral publicou um capítulo do livro Política alimentar, à época no prelo, sob a forma de artigo, intitulado "O que comemos e o que os outros comem", no suplemento "O Livro" da revista O Papel, em que comparou a alimentação do paulistano com a de europeus e de americanos. Informava que:

O baixo teor de proteínas, sobretudo das de procedência animal, bem como a reduzida taxa de gorduras, de cálcio e de vitaminas lipossolúveis, que registramos na dieta do paulistano, decorre sem dúvida, do deficiente consumo de carne, de ovos e de laticínios, gêneros de que, entre nós, se faz uso muito modesto, se considerarmos o que se passa em relação aos mesmos, em alguns países estrangeiros mais bem alimentados (POMPÊO DO AMARAL, 1944a: 7).

No livro Política alimentar (Imagem 3), editado em 1945, pela Brasiliense, Pompêo do Amaral cita os diagnósticos de educação alimentar e nutricional realizados em São Paulo com jovens estudantes e sua equipe de dietistas. No prefácio, o historiador Caio Prado Júnior enunciou:

O Sr. Pompêo do Amaral vai ao fundo do problema. Embora situando-se no terreno de sua especialidade, nele não se encerra. E por isso não procura soluções unicamente no setor restrito e próprio da questão alimentar. Suas vistas abrangem o conjunto do problema, e ele reconhece que a matéria da sua especialidade representa apenas um de seus aspectos. É nisto, sem dúvida, que reside a grande e principal mérito da contribuição que traz. Quando um técnico sabe colocar-se num ponto de vista amplo, e sua visão ultrapassa o setor da especialidade de que se ocupa, para situar-se no largo campo do conhecimento geral, ele une a técnica ao espírito filosófico, e realiza com isto a verdadeira obra científica (PRADO JÚNIOR, 1945: 3).

\footnotetext{
${ }^{7}$ Pompêo do Amaral informou que o texto de Josué de Castro referido era reprodução textual de uma notícia publicada no jornal A Gazeta, de 30 de maio de 1944.
} 
Esse livro está baseado em inquérito realizado com 793 famílias, correspondendo a um total de 5.053 pessoas, realizado inicialmente com 800 meninas do Instituto Profissional Feminino, no Brás, e que representavam a média da população paulistana, no tocante às condições de vida. Em 1940, a população paulistana era de um milhão e meio de pessoas. O inquérito foi realizado para conhecer de forma exata como se alimentavam e quais eram as condições alimentares da população da cidade de São Paulo. A partir da análise desse inquérito, Pompêo do Amaral e sua equipe pretendiam dar orientações às famílias para a correção e a promoção de uma alimentação saudável. Francisco Pompêo do Amaral denominou essa etapa em sua obra como "a alimentação da nossa gente e a de outros povos" (Ibid.: 9).

\section{Imagem 3}

Capa do livro Política alimentar, de 1945.

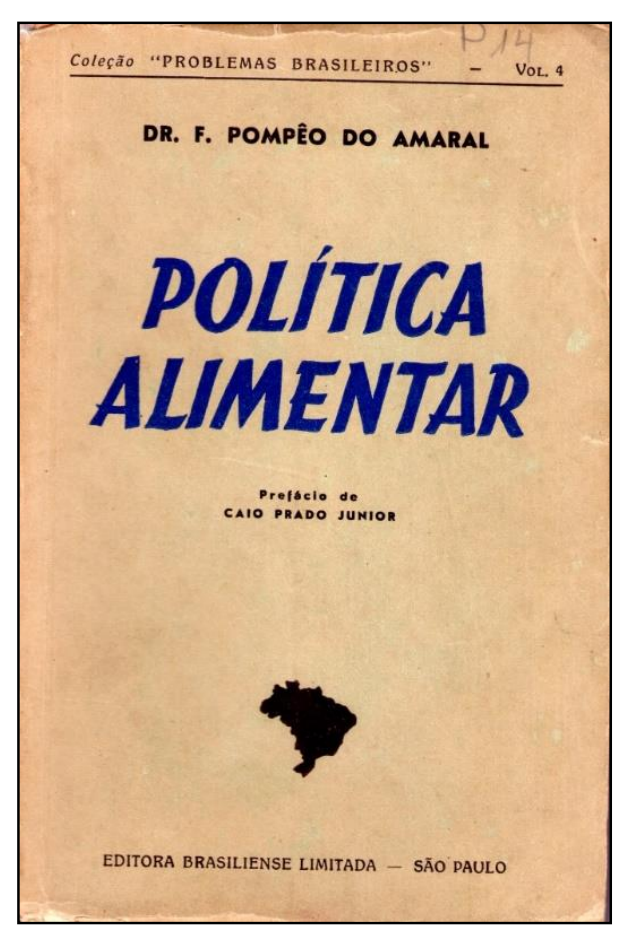

Fonte: POMPÊO DO AMARAL, 1945a: capa [reprodução].

O inquérito foi realizado com a aplicação de um questionário, que permitiu retratar as condições da população paulistana: identificação, condições higiênico-sociais, alimentação e observações. Foram montados mapas, apresentados na primeira "Exposição de Alimentação", em 1941, promovida pelo governo de São Paulo, nos pavilhões oficiais da Feira Nacional de Indústrias, que teve caráter puramente educativo, qual seja, o de ensinar o povo a alimentar-se bem e com economia. Nesse evento, a 
Superintendência do Ensino Profissional distribuiu folhetos e ofereceu um curso de divulgação dos preceitos e práticas de alimentação correta. Para demonstrar a "tragédia" de um povo desnutrido, Pompêo do Amaral apresentou, na obra Política alimentar, diversos quadros montados a partir de pesquisa bibliográfica em publicações da revista francesa Société des Nations (1936), de Pedro Escudeiro (1934 e 1939), e da Revista de Organização Científica (ca.1940), entre outros.

Na segunda parte da obra, intitulada "Política alimentar", que corresponde a dois terços do conteúdo do livro, Pompêo do Amaral descreveu e discutiu as dificuldades do empresariado brasileiro na questão da produção agrícola ou da ampliação do parque industrial, sempre sujeito à concorrência externa. Relata que nos tempos coloniais a produção de açúcar foi substituída pela mineração e pela criação de gado e de algodão.

Francisco Pompêo do Amaral considerava que as condições do mercado eram tão inconsistentes e transitórias que não permitiam encontrar meios de consolidar-se, faltando recursos e orientações técnicas para se estabelecer e concorrer com centros produtores mais adiantados no pós-guerra. Para a melhoria da alimentação popular e levando em conta a cultura alimentar e os preços de venda na época, propôs o desenvolvimento de práticas de educação alimentar e nutricional com a população, visando à seleção de alimentos adequados para uma alimentação saudável, reduzindo o desperdício.

Para a produção agrícola, propôs o desenvolvimento de práticas na agricultura que desestimulassem a mobilidade do agricultor e desenvolvessem a cultura do solo. Citou Rubens do Amaral, ao dizer que "o mais difícil vai ser convencer os nossos agricultores de que não há terras cansadas”, discutindo a importância da recuperação do solo na produção de alimentos saudáveis, em função da qualidade da composição dos nutrientes nesses alimentos. Pompêo do Amaral afirmou, nessa obra, que "Nossa produção agrícola e pastoril deve ser condicionada, em suas diretrizes, pelos interesses da alimentação pública, como já se faz em muitos países. Inverter essa ordem, por qualquer motivo, equivale a menosprezar o valor humano, de que depende o poderio físico, mental e econômico da nação" (POMPÊO DO AMARAL, 1945a: 88).

Pompêo do Amaral propôs melhorias na produção e comercialização do leite e seus derivados. Em meados da década de 1940, a venda do leite deveria seguir a classificação do leite (A, B e C), com os seguintes critérios: de inspeção do gado e dos estábulos, do tempo decorrente da ordenha até a entrega ao consumo e a temperatura em que o produto era mantido durante o armazenamento. 
Naquela época, o leite desnatado era desprezado no mercado, então Francisco Pompêo do Amaral demonstrou que esse produto tinha nutrientes que podiam melhorar a qualidade de alimentos e desenvolveu com a sua equipe de dietistas diversos tipos de pães. Acrescentando o leite desnatado nas receitas, demonstrou que houve aumento no teor de proteínas desse tipo de produto. Propôs, para a panificação, a redução da farinha de trigo, sugerindo a sua substituição parcial na fabricação de pães por farinhas de milho, soja ou mandioca, discutindo as propriedades desses diferentes produtos durante o processo de fabricação e considerando que o pão era primordial na mesa do brasileiro. Demonstrou que o milho não era inferior ao trigo no que dizia respeito ao seu valor nutritivo e à sua digestibilidade.

Quanto às políticas públicas, Francisco Pompêo do Amaral sugeriu, em Política alimentar, alterações na legislação sanitária vigente, de modo a evitar fraudes na produção industrial de alimentos, referindo-se, principalmente, à produção de manteigas, cuja legislação da época apresentava um amplo leque de classificação para o produto. Permitia-se a mesma denominação de manteiga para produto contendo mistura de óleo vegetal hidrogenado, acrescido inclusive de corantes, apresentando coloração aprazível ao consumidor. Para garantir a segurança alimentar e nutricional do povo brasileiro, o médico propôs a criação de estoque regulador (para evitar falta de alimentos em período sazonal) pelo governo federal, medida que contribuiria para o planejamento da produção agrícola. Segundo Pompêo do Amaral:

Toda política alimentar realmente salutar terá de alicerçar-se, por força, no postulado enunciado. Daí decorre a necessidade de estimular-se o desenvolvimento da capacidade aquisitiva de nossa população, criando-se mercado interno de gêneros alimentícios com bases sólidas e capazes de incentivar a produção para mantê-lo. Mas, como a capacidade aquisitiva é sabidamente corolário da produção, fácil é inferir-se que estamos envoltos num círculo vicioso. Até o momento, por escassa capacidade aquisitiva, não temos tido mercado interno, nem boa alimentação. Também a mão de obra mal alimentada é pouco rendosa, apenas capaz de produção exígua. Precisamos chegar a modificar essa situação anti-higiênica, antieconômico e antissocial, buscando simultaneamente promover a boa alimentação e desenvolver a capacidade de produção e de aquisição (1945a: 88). 
Pompêo do Amaral, na década de 1950, continuou pesquisando e publicando livros, bem como elaborando comunicações para a Revista de Medicina e Cirurgia de São Paulo.

No ano de 1953, o curso do qual Pompêo do Amaral era professor, "Formação de Professoras de Educação Doméstica e Auxiliares em Alimentação”, foi desmembrado, em 9 de outubro, por meio da Lei Estadual $\mathrm{N}^{\circ} 2.318$, resultado de um projeto de lei do ex-deputado Arnaldo Laurindo. No curso de "Auxiliares em Alimentação", que, posteriormente, foi denominado "Formação de Dietistas", Francisco Pompêo do Amaral foi professor da cadeira de Dietética entre 17 de maio de 1939 e 17 de janeiro de 1958.

Francisco Pompêo do Amaral escreveu a obra A alimentação em São Paulo no período de 1940 - 1951 e encaminhou-a para o Serviço de Alimentação da Previdência Social, no Rio de Janeiro, para participar de um concurso para encontrar o melhor livro científico sobre alimentação. O prospecto de divulgação desse concurso, em 1954, informava que:

Instituindo o 'Prêmio Nacional de Alimentação' - a mais elevada láurea científica de nosso país - como estímulo as pesquisas e aos estudos a respeito de questões alimentares, oferece o SAPS, anualmente, aos nossos homens de ciência uma recompensa aos seus esforços realizados no silêncio dos laboratórios, abrindo-lhes, ao mesmo tempo, a possibilidade de trazerem a público o resultado de suas pesquisas, uma vez que, de acordo com o regulamento do concurso, é assegurado aos autores a edição da obra premiada. Importante já e, sem dúvida, o acervo de contribuições incorporadas à moderna Nutrologia pelos cientistas laureados pelo SAPS e que hoje enriquecem o patrimônio científico e cultural do país, elevando o conceito em que já é tido o Brasil no campo dos estudos e pesquisas alimentares (BRASIL, 1954: s.p.).

A leitura de A alimentação em São Paulo no período de 1940 - 1951, premiada em 1954 pelo SAPS, permite identificar que Francisco Pompêo do Amaral e sua equipe de dietistas, Neide Gaudenci de Sá, Debble Smaíra Pasotti, Yonne Cintra de Souza, Dalva Maria Oliani, Eunice de Oliveira e Arcelina Ribeiro, empregaram as práticas escolares e pedagógicas desenvolvidas com as alunas do curso de "Auxiliares em Alimentação" para realizarem os inquéritos socioeconômicos alimentares e, a partir das mesmas, as pesquisas que propiciaram a elaboração da obra. O livro trazia os resultados dos 
inquéritos realizados entre as famílias de alunas e alunos das duas escolas técnicas da capital, atualmente denominadas Escola Técnica Estadual Carlos de Campos e Escola Técnica Estadual Getúlio Vargas, e constava em sua apresentação:

Reunindo em volume os relatórios e as conclusões dos inquéritos realizados durante o período compreendido entre 1940 e 1951, temos em mira proporcionar a médicos, higienistas, sociólogos, economistas, educadores, etc., úteis informes sobre as condições de alimentação da população paulistana, que é sabidamente a de padrão de vida mais elevado do país. Baseiam-se tais relatórios em investigações, que se processaram durante mais de um decênio e permitem não só o reconhecimento da situação, em determinado momento, mas ainda possibilitam divisar o sentido em que esta evolui. Que possa nosso trabalho, de qualquer maneira, contribuir para esclarecer sobre assunto tão relevante todas as pessoas que zelam pelo bemestar da coletividade que constituímos - é o que podemos desejar (POMPÊO DO AMARAL, 1960: 6).

Ainda no Departamento de Ensino Profissional do estado de São Paulo, Pompêo do Amaral recebeu dois prêmios da "Academia Nacional de Medicina". O primeiro, em 1955, referente ao trabalho O leite. Problema nacional (POMPÊO DO AMARAL, 1957) e, o segundo, em 1956, com O problema da alimentação: aspectos médico-higiênicosociais (POMPÊO DO AMARAL, 1963a), ambos publicados em livro pelo editor José Olympio.

Francisco Pompêo do Amaral, com o editor Caio Prado Jr., Josué de Castro e outros colaboradores, fundou a Revista Brasiliense, em 1955, que funcionava na Rua Barão de Itapetininga ${ }^{\circ} 93,12^{\circ}$ andar, em São Paulo, até dezembro de 1965, período do seu encerramento (MONTALVÃO, 2010).

Pompêo do Amaral publicou vários artigos nessa revista. Em "A Fome - Tema Proibido...", de novembro-dezembro de 1955, ele demonstrou a sua atuação enquanto intelectual, que estudava muito e quando escrevia buscava sempre informar a população sobre a importância de uma alimentação saudável:

[...] De Guilherme de Piso, que veio com NASSAU, a Gouveia e Gama Lôbo, no século passado, se reconheceu e, por vezes, se atribuiu à má alimentação a ocorrência de moléstias hoje bem caracterizadas como carências. [...] Luis 
Amaral se reporta à transferência aos colonos dos conhecimentos de química agrícola de que disporiam os índios: "Foi com eles que aprendemos esse processo de adubar o solo por meio de queimadas, processo destruidor e bárbaro, não duvido, mas com o qual temos enriquecido, sem o qual seria impossível a agricultura em nossas matas, e que ainda é o mais geral em todo o Brasil". [...] A qualquer estrangeiro que aportasse ao Brasil em tempos coloniais e mesmo depois de nossa independência, chamavam a atenção as péssimas condições de alimentação da ração de nossas mais importantes cidades (POMPÊO DO AMARAL, 1955).

Francisco Pompêo do Amaral empregou em seus artigos as práticas escolares e pedagógicas que realizou, enquanto professor de Dietética, e diretor do curso de "Auxiliares em Alimentação", como demonstra o artigo "O escasso desenvolvimento somático e mental dos escolares desnutridos”, publicado na Revista Brasiliense de março e abril de 1956,

[...] Ainda em maio de 1944, o Dr. José Queiroz Guimarães, do Departamento de Saúde Escolar de São Paulo, afirmou solenemente pela imprensa que "o estado de nutrição da maioria dos escolares paulista é assustador" e admitiu que no "cômputo geral, 80\% deles sejam desnutridos". [...] Acreditamos, todavia, que a desnutrição se revela, de maneira mais segura e insofismável, quando traduzida por sensível redução do peso e da estatura das crianças. [...] Vimos realizando, no Serviço de Alimentação e Higiene Escolar do Departamento de Ensino Profissional de São Paulo, pesquisas sobre a frequência da desnutrição entre nossos escolares. Nelas, vimos considerando como casos de desnutrição aqueles em que se verificam desvios de talhe ou de peso que importam em, pelo menos, $10 \%$ de cifras da tabela de valores normais adotados. Trata-se de critério seguro na medida do possível e não de simples indício ou sinal de probabilidade de desnutrição. E os resultados, que temos obtidos em pesquisas mais recentes nos permitem assegurar que oscila entre 11 e $15 \%$ a incidência de desnutrição entre as crianças de meio que retrata bem a média das condições vigentes no seio de todo a população da cidade em que vigoram condições econômicas menos desfavoráveis, em todo o nosso país. [...] Pesquisas semelhantes realizou a dietista Neide Gaudenci, de nosso Serviço, com a aluna Aldonia Cekannaskas, em outro asilo, no ano 
de 1952, verificando que, de 28 meninas pesadas e medidas, 8 , ou seja $29 \%$, eram desnutridas (POMPÊO DO AMARAL, 1956: 163-167).

A capa da segunda edição do livro Coma e engorde!, de 1958, trazia um destaque sobre sua finalidade, "um guia prático para todos aqueles que desejam alimentar-se cientificamente e gozar boa saúde" (POMPÊO DO AMARAL, 1958). Esse livro era composto de doze capítulos e o primeiro se referia à magreza brasileira, sobre a qual Francisco Pompêo do Amaral escreveu:

Certo dia, depois que me despedi do diretor da Editora Brasiliense, fiquei pensando se valia a pena aceitar o convite com que me quis distinguir. Pedirame que lhe escrevesse um livro sobre a magreza e sobre a maneira de combatêla. Escrever não me parecia difícil. Todavia, fiquei por muitos dias hesitante. E isso porque duvidava do alcance de qualquer trabalho nesse sentido, para o nosso meio. O leitor pode achar estranha a dúvida. Talvez me dê razão, ao cabo de algumas explicações. Tornara-me pessimista porque depois de quase três lustros de clínica, depois de realizar pesquisas sobre a alimentação, os salários, os orçamentos das famílias, depois de ter procurado conhecer detalhadamente até a produção, a distribuição de alimentos, etc. -chegara eu a uma conclusão melancólica. [...] Contrariamente ao que muita gente pensa, o médico não pode resolver sempre os problemas que lhe são propostos. Como alimentar convenientemente - como engordar - a quem ganha mal para comer um pouco de arroz e feijão, alimentos que, hoje, constituem o cardápio forçado dos que já não têm nem pão? Como alimentar convenientemente aqueles que muito pouco comiam carne e leite e que só podem obtê-los, agora, de vez em quando? Há, sem dúvida, grande número de casos de magreza que saem, por completo, da alçada do médico. [...] Os magros precisam entender. A despeito de sua qualidade de 'pessoa' ou 'coisa' abstrata, Deus é de propriedade dos gordos. E pior do que isso. É arma que se emprega contra os magros. Quantas bordoadas têm estes tomados, quantos massacres tem havido, em nome da salvação da chamada civilização cristã?! Para os magros impossibilitados de engordar - os quais têm toda a minha simpatia e toda a minha solidariedade não darei, pois, mais do que um conselho. Que se organizem... (POMPÊO DO AMARAL, 1958: 7-12). 
O prestígio do professor Francisco Pompêo do Amaral é notório como escritor, nutrólogo e sociólogo (Imagem 4). Quando a Livraria José Olympio Editora fez trinta anos, o escritor Pelegrino Junior publicou um artigo no Jornal do Brasil, de 25 de novembro de 1961, recordando os médicos editados por José Olympio, na relação estava Pompêo do Amaral (VILLAÇA, 2001: 221).

\section{Imagem 4}

Capas dos livros O leite. Problema nacional, de 1957, A alimentação em São Paulo no período de 1940-1951, de 1960, e O problema da alimentação, de 1963.
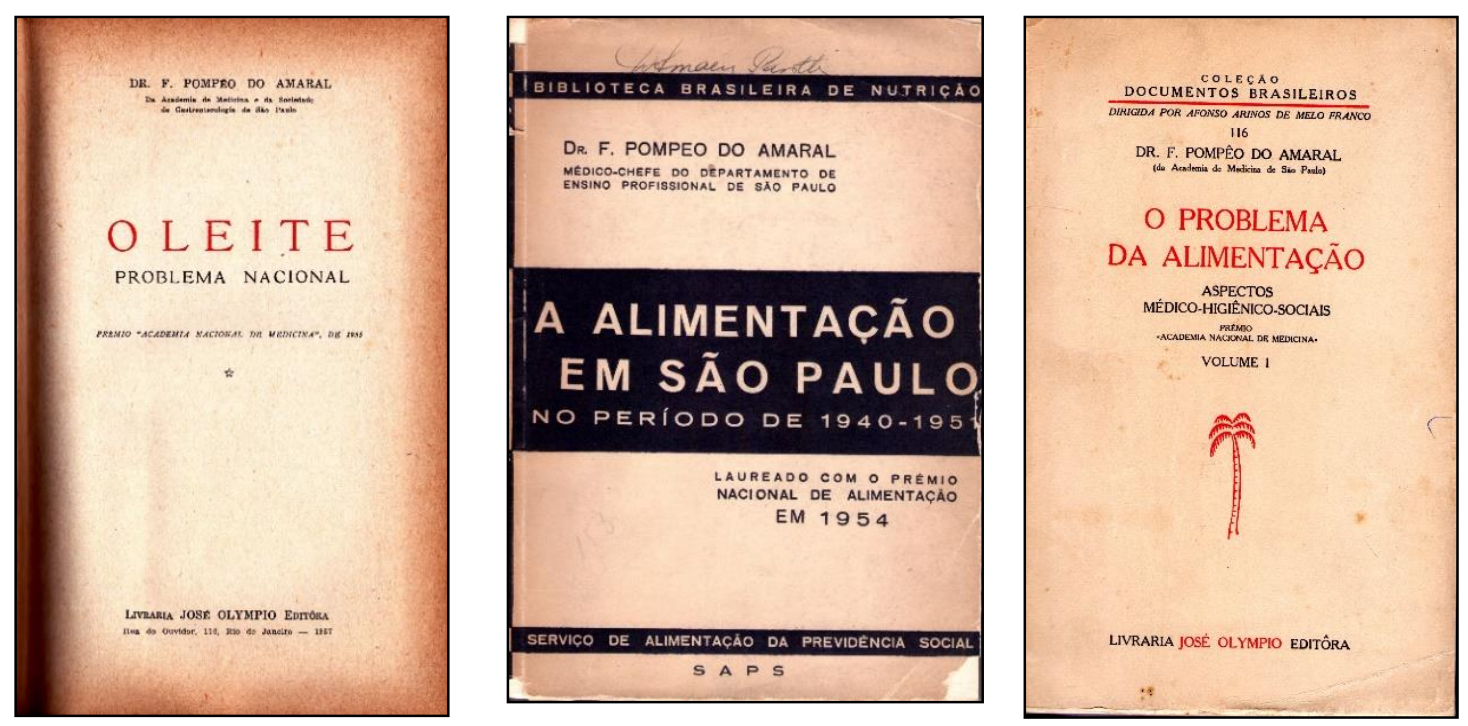

Fontes: POMPEO DO AMARAL, 1957: capa; Idem, 1960: capa; e Idem, 1963a: capa [reprodução].

Pode-se dizer que Pompêo do Amaral era um cientista, tendo recebido três prêmios nacionais por suas pesquisas, e um intelectual, por articular as suas práticas em educação com os problemas sociais do país. Segundo Vieira Pinto, “o intelectual é a consciência da realidade, dispondo de uma atividade racional que organiza a história, dá corpo à nação, funda o poder. $\mathrm{O}$ intelectual, mediado pelo Estado, desperta a razão que prevê o futuro, encurta o tempo e preconiza o planejamento, justificando teoricamente todo esse quadro" (apud MENDONÇA et al., 2006: 98).

Francisco Pompêo do Amaral se aposentou em janeiro de 1961, deixando o Departamento de Ensino Profissional (CARVALHO, 2013a).

Em 1985, o povo brasileiro teve restabelecida a liberdade democrática e pôde voltar a se expressar novamente. Francisco Pompêo do Amaral voltou a publicar livros e 
em revistas. Em 1986, publicou Discriminação e mistificação em alimentação. A FAO, a OMS, etc. contra os povos subdesenvolvidos. Logo na introdução da obra, o médico explica os motivos que o levaram a publicá-la:

Desde o último pós-guerra, vêm surgindo em outros países - que costumam, entre nós, ser considerados 'bons vizinhos' ou 'aliados' - planos que têm em vista alienar a alimentação dos povos subdesenvolvidos para que se torne possível deles subtrair produtos que contribuam para manter o alto padrão de nutrição - e, por conseguinte, de saúde e bem-estar - de povos privilegiados, que sentem ameaçada sua hegemonia. Essa denúncia séria, muito grave mesmo, já fizemos há mais de vinte anos, em algumas páginas de volumosa obra. E nela insistimos, agora, porque, no espaço de tempo se escoou, se fez ainda mais necessária. Certas organizações científicas ou não - dizíamos com rótulos internacionais ou ligadas declaradamente as nações poderosas e altamente industrializadas, se empenham em demonstrar que os alimentos animais - o leite, o queijo, a carne, o ovo - não seriam importantes quanto se tem acreditado até agora, para a alimentação humana, e poderiam muito bem ser substituídos por soja, algas, etc., senão com vantagens, pelo menos, sem maiores inconvenientes, na alimentação dos chamados povos subdesenvolvidos, por cuja saúde e por cuja eficiência física e mental não zelam, de fato, com o carinho de que fazem alarde. Observa-se, ao contrário, de maneira nítida, nesta fase evolutiva da Nutrologia, pronunciada tendência ao estabelecimento de planos de alimentação para povos subdesenvolvidos, e mesmo para coletividades e indivíduos de escassos recursos econômicos, diferentes daqueles que se sugerem para povos, coletividades e indivíduos de condições econômicas privilegiadas (POMPÊO DO AMARAL, 1986: XI) ${ }^{8}$.

Nesse livro, de 1986, Francisco Pompêo do Amaral esclareceu o que aconteceu no II Congresso Brasileiro de Nutricionistas, realizado em São Paulo, em julho de 1960. Como membro ativo e palestrante, ao intervir nas discussões de uma mesa redonda sobre a utilização da soja na alimentação humana, após ter proferido um dos dois discursos oficiais da reunião de encerramento do congresso, promovido pela Associação de Nutricionistas da Universidade de São Paulo e pela Associação de Dietistas do Estado de São Paulo (CONGRESSO, 1962:62-69 e 131-134), afirmou:

\footnotetext{
${ }^{8}$ Francisco Pompêo do Amaral refere-se, em nota, a sua obra O Problema da Alimentação. Aspectos médico-higiênicos-sociais (1963a: XI).
} 
Naturalmente prosseguimos, e com mais vivacidade, nossa luta contra essa mistificação. Afora inúmeros artigos e entrevistas veiculados pela imprensa diária, debatemos o assunto em congresso (II Congresso Brasileiro de Nutricionistas, de Julho de 1960, São Paulo), que nos deixou anais tendenciosamente mal estenografados e não revistos, mas que, mesmo assim, permitem ideia de que lá se passou. Um dos vários artigos que, a propósito, escrevemos para a histórica Revista Brasiliense ("Soja - Instrumento de Imperialismo", de 26: 42-58, 1959) foi reproduzido em página inteira do histórico O Semanário, (191: 26-XII-1959 a 1-I-1960). O Departamento Nacional da Criança consultou-nos, a propósito. E assim fizemos proselitismo. Nosso sempre lembrado José Bonifácio de Souza Amaral, eminente economista, escreveu artigos expressando solidariedade com nossos pontos de vista. Outros dois combativos jornalistas - Wilson Rahal (Última Hora, 20-VIII-1960) e o saudoso Prof. Alberto Rovai - também reproduzindo nossa opinião a respeito, trataram do assunto com veemência. O último deles, participando do Seminário Ensino Supletivo, apresentou moção subscrita por cerca de 80 congressistas, sugerindo que a Secretaria da Educação vedasse, nos estabelecimentos mantidos pelo Estado, a propaganda da soja como substituto de qualquer alimento habitual no cardápio popular (Diário de S. Paulo, 30-IX-1959). Também um médico e jornalista ilustre Eduardo Maffei, teceu oportunos comentários em sua coluna (Diário de S. Paulo, 12-IX-1959), em reforço à nossa posição. E lembrou que, "nem nos tempos dos germanos que metiam medo às legiões de César e muito menos nos de Salazar, qualquer um ouviu dizer que o governo se preocupasse, com seus cientistas, em modificar a alimentação do seu povo". Houve ainda outros que não se omitiram em defesa da causa. Evidentemente nossa denúncia foi recebida com tanto interesse porque, no caso, como dissemos inclusive em entrevista ao Correio Paulistano (27-IX-1959), afora os aspectos médico, higiênico, econômico, social e político, havia um claro aspecto moral, que sobreleva os demais (POMPÊO DO AMARAL, 1986: 124) ${ }^{9}$.

Francisco Pompêo do Amaral foi um profissional articulado politicamente com as associações de classe. Como médico foi um dos trinta membros titulares da Sociedade de

\footnotetext{
${ }^{9}$ Pompêo do Amaral cita nesse texto as referências bibliográficas de suas fontes como a Revista Brasiliense e as reportagens jornalísticas empregadas na elaboração da obra Discriminação e Mistificação em Alimentação (1986: 124).
} 
Medicina e Cirurgia de São Paulo e na revista desta sociedade publicou diversos artigos. Com a população, articulou-se, por meio de suas matérias jornalísticas, sobre alimentação e nutrição publicadas na imprensa. Após a sua aposentadoria no Departamento de Ensino Profissional, em 1961, este médico continuou atuando no campo da alimentação e nutrição e escrevendo artigos para revistas conceituadas, sendo eleito como membro correspondente nacional da Academia Nacional de Medicina, em 30 de junho de 1969. O seu trabalho foi interrompido com o seu falecimento, em 1990, em São Paulo, mas sempre será lembrado como um pioneiro no campo da alimentação e nutrição no Brasil.

\section{Fontes}

AMARAL, Rubens (1939) Prefácio. In: POMPÊO DO AMARAL, Francisco (1939b). Comer para viver. Alimentos - Princípios imediatos - Sais minerais. Trabalho da Secção de Alimentação e Nutrição da Superintendência do Ensino Profissional. São Paulo: Empresa Gráfica da Revista dos Tribunais

BRASIL. SERVIÇO NACIONAL DA PREVIDÊNCIA SOCIAL (1954). Prospecto de divulgação do Prêmio Nacional de Alimentação do Serviço de Alimentação da Previdência Social.

CONGRESSO BRASILEIRO DE NUTRICIONISTAS (1962). Anais do II Congresso Brasileiro de Nutricionistas. São Paulo: s.e..

POMPÊO DO AMARAL, Francisco (1939). Os cursos de Dietética. Organizados e inaugurados na Superintendência do Ensino Profissional. Santos: Edição do Instituto D. Escolástica Rosa. Escola Profissional Secundária, maio.

(1939a). Aula inaugural. Santos: Edição do Instituto D. Escolástica Rosa.

Disponível

em:

<http://www.cpscetec.com.br/memorias/livros/carloscampos/livro_cacaco.pdf/>. Acesso em: 28 mar. 2015.

(1939b). Comer para viver. Alimentos - Princípios imediatos - Sais minerais. Trabalho da Secção de Alimentação e Nutrição da Superintendência do Ensino Profissional. São Paulo: Empresa Gráfica da Revista dos Tribunais.

(1941). O fubá integral e a alimentação do povo brasileiro. Revista Agrícola Brasileira, São Paulo, out., pp. 398-399.

(1941a). Alimentação - conferências. Trabalho da Seção de Alimentação e Nutrição da Superintendência do Ensino Profissional. Publicação n ${ }^{\circ}$ 25. [São Paulo]: Curso de Artes Gráficas do Instituto D. Escolástica Rosa. Escola Profissional Secundária.

(1942). Frutas e verduras para o povo. O leite desnatado em alimentação. O cálcio na economia orgânica. O leite higienicamente obtido pode ser consumido cru. Revista Agrícola Brasileira, São Paulo, abr., pp. 19-25.

(1942a). As relações da agronomia e da zootécnica com a alimentação. Revista Agrícola Brasileira, São Paulo, jun., pp. 100-103.

(1942b). A alimentação do paulistano. Revista Agrícola Brasileira, São Paulo, out., pp. 261-263.

(1942c). Que pode ter a manteiga? Revista Agrícola Brasileira, São Paulo, dez., pp. 353-355. 
(1942d). A vitamina “ $A$ ". Esse fator alimentar e os estados patológicos consequentes à carência do mesmo. Secretaria da Agricultura, Indústria e Comércio do Estado de São Paulo. Diretoria de Publicidade Agrícola. São Paulo.

[1942]. Uma ação triunfante [Folha da Manhã]. Livro de Recortes de Jornais. Centro de Memória da Escola Técnica Estadual Carlos de Campos, s.d.

(1944). A alimentação da população no momento que atravessamos. Revista de Medicina e Cirurgia de São Paulo, jul.-ago., pp. 27- 38.

(1944a) O que comemos e o que os outros comem. Revista O Papel, vol. VI, mar., pp. 7-9.

(1945). A Faculdade de tipo norte-americano, que agora temos. Revista de Medicina e Cirurgia de São Paulo, jul.-ago., pp. 240- 243.

(1945a). Política alimentar. São Paulo, Editora Brasiliense Limitada.

(1955). A Fome - tema proibido.... Revista Brasiliense, nov.-dez., pp. 146-159.

(1956). O escasso desenvolvimento somático e mental dos escolares desnutridos.

Revista Brasiliense, mar.-abril, p. 163-168.

(1957). O leite. Problema nacional. Rio de Janeiro: Livraria José Olympio Editora. (1958). Coma e engorde. 2 ed. São Paulo: Editora Brasiliense.

(1960). A alimentação em São Paulo no período 1940 - 1951. Rio de Janeiro: Companhia Liverte Industrial.

(1963a). O problema da alimentação. Aspectos Médico-Higiênico-Sociais. Rio de Janeiro: Livraria José Olympio Editora.

(1963b). Trabalhos e títulos do Doutor Francisco Pompêo do Amaral, para concorrer a membro correspondente nacional, 4 de agosto. Acervo do Arquivo da Academia Nacional de Medicina. Rio de Janeiro.

(1986). Discriminação e mistificação em alimentação. A FAO, A OMS, etc. contra os povos subdesenvolvidos! São Paulo: Editora Alfa-Omega.

MEIRA, João Alves (1939). Discurso na posse de Francisco Pompêo do Amaral na Sociedade de Medicina e Cirurgia de São Paulo. Boletim da Sociedade de Medicina e Cirurgia de São Paulo, vol. 23, n 7-8, jul.-ago., pp. 218-220.

PRADO JÚNIOR, Caio (1945). Prefácio. In: POMPÊO DO MARAL, Francisco. Política alimentar. São Paulo, Editora Brasiliense, pp. 1-3.

\section{Referências bibliográficas}

BARONI, Gabriel Vinicius (2014). Historiadores e intelectuais do Oeste Paulista nas décadas de 1940 e 1950. Intellèctus, vol. XIII, n.1, pp. 24-33. Disponível em: <http://www.intellectus.uerj.br/Textos/Ano13n1/Gabriel_Vinicius_Baroni.pdf>. Acesso em: 28 mar. 2015.

CARVALHO, Maria Lucia Mendes; FAGNANI, Maria Angela (2014). Francisco Pompêo do Amaral: sujeito social e seus objetos de ensino em prol da alimentação e nutrição no Brasil. Revista Linhas (Florianópolis. Online), vol. 15, n. 8, pp. 100$126 . \quad$ Disponível em: $<$ http://periodicos.udesc.br/index.php/linhas/article/viewFile/19847238152820141 00/3104>. Acesso em: 28 mar. 2015.

CARVALHO, Maria Lucia Mendes (2013). Desvendando raízes e retratos no campo da alimentação e nutrição no Brasil: de Francisco Pompêo do Amaral ao Centro Paula Souza. Tese (Doutorado em Planejamento e Desenvolvimento Rural Sustentável). 
Faculdade de Engenharia Agrícola, Universidade Estadual de Campinas, Campinas.

. (2013a). Saúde, Alimentação e Nutrição: os refeitórios nas escolas profissionais (1939 a 1961) In: CARVALHO, Maria Lucia Mendes (org.). Patrimônio, currículos e processos formativos. São Paulo: Centro Paula Souza. Imprensa Oficial. <http://www.cpscetec.com.br/memorias/arquivos/curriculos.pdf $>$. Acesso em: 28 mar. 2015.

LAURINDO, Arnaldo (1962). 50 anos de Educação Profissional. Estado de São Paulo. 1911 a 1961. São Paulo: Editora Gráfica Irmãos Andrioli S.A., 2 v.

MASSUCATO, José Geraldo; BARBANTI, Valdir José (1999). Histórico da Escola de Educação Física e Esporte da Universidade de São Paulo. Revista Paulista de Educação Física, São Paulo, vol. 13, pp. 7-12, dez. Disponível em: <http://citrus.uspnet.usp.br/eef/uploads/arquivo/v13\%20esp\%20artigo1.pdf>. Acesso em: 28 mar. 2015.

MELO, Marcelo Mário de; NEVES, Teresa Cristina Wanderley (org.) (2007). Josué de Castro. Perfis Parlamentares 52. Brasília: Câmara dos Deputados, Coordenação de Publicações.

MENDONÇA, Ana Waleska P. C. et al. (2006). Pragmatismo e desenvolvimento no pensamento educacional brasileiro dos anos de 1950/1960. Revista Brasileira de Educação, vol. 11, n.31, jan/abr. Disponível em: <http://www.scielo.br/pdf/rbedu/v11n31/a08v11n31.pdf>. Acesso em 28 mar. 2015.

MONTALVÃO. Sérgio de Sousa. Notas sobre uma publicação comunista independente: a Revista Brasiliense. Revista Urutágua, ${ }^{\circ}$ 10, ago./set./out./nov. Disponível em: $<$ http://www.urutagua.uem.br/010/10montalvao.pdf >. Acesso em: 28 mar. 2015.

MOTT, Maria Lucia (2003). Estudos bibliográficos e filantropia: uma reflexão a partir da trajetória de vida de Pérola Byington. Revista Niterói, vol.3, n.2, pp.21-41, 2003. Disponível em: <http://www.ieg.ufsc.br/admin/downloads/artigos/02112009012005mott.pdf>. Acesso em: 28 mar. 2015.

TENCA, Álvaro (2006). Senhores dos trilhos. Racionalização, trabalho e tempo livre nas narrativas de ex-alunos do Curso de Ferroviários da Antiga Paulista. São Paulo: Editora UNESP.

VILLAÇA, Antônio Carlos (2001). José Olympio. O descobridor de escritores. Rio de Janeiro: Thex Editora.

Artigo recebido em 30 de março de 2015.

Aprovado em 15 de junho de 2015.

DOI: $10.12957 /$ intellectus.2015.18800 